\title{
Descriptive sensory profile of cow and buffalo milk Cheddar cheese prepared using indigenous cultures
}

\author{
M. A. Murtaza, ${ }^{* 1}$ S. U. Rehman, † F. M. Anjum, $†$ and N. Huma \\ *Institute of Food Science and Nutrition, University of Sargodha, Sargodha-40100, Pakistan \\ †National Institute of Food Science and Technology, University of Agriculture, Faisalabad-38040, Pakistan
}

\begin{abstract}
The objective of the study was to compare the sensory profile of Cheddar cheese prepared from cow and buffalo milk using indigenous and commercial cultures. Commercially available and locally isolated, indigenous starter cultures were used to prepare cow and buffalo milk Cheddar cheese. The cheese was ripened at 4 and $12^{\circ} \mathrm{C}$ and analyzed for descriptive sensory profile by a panel of 10 assessors after 60 and $120 \mathrm{~d}$ of ripening. On evaluation, the mean scores for odor, flavor, and texture attributes obtained for buffalo milk cheese were significantly higher than those obtained for cow milk cheese. For most of the traits, cheese samples prepared from indigenous cultures and ripened at higher temperature received higher descriptive scores compared with those of commercial cultures and ripened at lower degrees. Milk sources highly significantly affected the "creamy" and "sour" traits of odor; the "creamy," "smoky," and "soapy" flavors; and all the texture attributes except "maturity." Starter cultures considerably influenced the production of "acidic," "bitter," "sweet," and "sour" characteristics. The use of elevated ripening temperature showed noticeable effect on all the characteristics except the "creamy" odor and flavor. Principal component analysis and hierarchical cluster analysis also showed that milk sources, starter cultures, and ripening temperatures significantly influenced the sensory characteristics.
\end{abstract}

Key words: Cheddar cheese, cow milk, buffalo milk, sensory evaluation

\section{INTRODUCTION}

Starter cultures and milk composition are key factors affecting Cheddar cheese quality (Varnam and Sutherland, 1994). The starter cultures are used to promote acid development during curd manufacturing and also to confer distinct textural and flavor properties (Mc-

Received July 29, 2012.

Accepted November 29, 2012.

${ }^{1}$ Corresponding author: anjum_ft@yahoo.com or mian.anjum@uos. edu.pk
Sweeney and Sousa, 2000). Milk composition is influenced by species, breed, individuality, nutritional status, health, and stage of lactation of producing animals (Fox et al., 2000). Buffalo milk is rich in fat, lactose, caseins, calcium, magnesium, and phosphate compared with cow milk (Fundora et al., 2001; Ahmad et al., 2008) and, because of its chemical composition, it offers excellent opportunities for the development of different dairy products (Murtaza et al., 2008). Worldwide, Cheddar cheese is produced from cow milk, but buffalo milk ranks at the top in Pakistan's milk production and is more suitable for cheese manufacturing (Murtaza et al., 2012).

Cheddar is a hard cheese that undergoes a complex series of chemical, bacterial, and enzymatic reactions during ripening (Singh et al., 2003; Farkye, 2004), which are responsible for the development of sensory characteristics that are typical of ripened cheese (Pollard et al., 2003; Smit et al., 2005; Azarnia et al., 2006).

Ripening of cheese is an expensive and timeconsuming process (Law, 2001; Murtaza et al., 2012), influenced by altered ripening times (Fox, 1989), use of enzymes (Wilkinson, 1993), use of various starter cultures in different combinations (Lee et al., 1990), and various ripening temperatures (Rehman et al., 2000). Attempts to shorten the ripening time using a range of ripening systems have had varying degrees of success (Wilkinson, 1993; Law, 2001). The use of elevated ripening temperatures is technically the simplest strategy to accelerate cheese ripening but, in spite of being recognized as beneficial for many years, it is still not widely used commercially (Law, 2001; Hannon et al., 2005; Murtaza et al., 2012).

Assessment of the degree of ripening and various sensory characteristics is an important part of cheese quality evaluation and currently involves the use of trained sensory panelists or individuals (Downey et al., 2005). Grading and judging are used extensively for sensory evaluation of dairy products (Bodyfelt et al., 1988); a product is evaluated based on the presence or absence of specific attributes and on overall quality score. These quality scores are usually based on the opinions of one individual, and the quality score is subjective rather 
than specifically defined (Drake et al., 2005; Caspia et al., 2006).

The traditional approach to sensory analysis reveals little or no information on the complex flavor attributes of the cheese or what factors affect those attributes and does not enable direct comparisons between the results obtained from different studies. However, modern sensory techniques allow the key attributes of the cheese to be objectively determined and described (Hannon et al., 2005).

Descriptive evaluation by a panel of trained assessors is a modern technique for determining the sensory profile of a cheese and evaluating the influence of processing changes on individual sensory characteristics (Fox et al., 2000). It is a sophisticated sensory test method that creates a total sensory description of a product (Stone and Sidel, 1985). This methodology can be used to determine the effect of individual components on scores of descriptors of a complex product. Descriptive analysis has been used to study a variety of products, including cheese (Heisserer and Chambers, 1993). Omission testing removes one component at a time from a product, creating a series of samples, to estimate the effect of components on the attributes of the product (House and Acree, 2002).

Principal component analysis (PCA) and hierarchical cluster analysis (HCA) are forms of multivariate statistical analysis useful for studying correlation in a set of measurements of a given number of variables for a determined number of assessors. Multivariate methodology can be applied to reduce a large number of variables to a smaller subset. The techniques retain variables that contribute significantly to important components and discard those variables that contribute mainly to unimportant components (Hannon et al., 2005).

The study was designed with the objectives (1) to compare the sensory quality of cow and buffalo milk Cheddar cheese and (2) to assess the influence of commercially available and locally isolated starter cultures and elevated ripening temperature on descriptive sensory profile.

\section{MATERIALS AND METHODS}

\section{Milk and Starter Cultures}

Cow and buffalo milk samples were procured from a farmhouse (research herd), Institute of Animal Nutrition and Feed Technology, University of Agriculture, Faisalabad, Pakistan. Milk samples were standardized at $4.0 \%$ fat level and analyzed for composition following the standard procedures of AOAC (1990). Commercially available (Chr. Hansen Ireland Ltd., Little Island,
Co. Cork, Ireland) and indigenous (locally isolated in Biotechnology Laboratory, National Institute of Food Science and Technology, University of Agriculture, Faisalabad, Pakistan) cultures of Lactococcus lactis ssp. cremoris and Lactococcus lactis ssp. lactis were used in combination at a ratio of 95:5.

\section{Cheese Manufacturing and Ripening}

Cheddar cheese was manufactured from cow and buffalo milks (3 samples from each, $50 \mathrm{~L} /$ sample) using commercially available and locally isolated starter cultures following the standard method described by Scott (1981). The cheese samples were ripened at 4 and $12^{\circ} \mathrm{C}$ for a total period of $120 \mathrm{~d}$.

\section{Descriptive Sensory Evaluation}

Descriptive sensory evaluation was done for cheese samples after 60 and $120 \mathrm{~d}$ of ripening by a panel of 10 assessors drawn from faculty members and postgraduate students of National Institute of Food Science and Technology, University of Agriculture, Faisalabad, Pakistan, following the method detailed by Muir and Hunter (1992). The assessors were first trained (in 5 sessions) on different commercially available cheese samples and a descriptive sensory language was developed for different parameters (odor, flavor, and texture) of cheese. The cheese samples under study were then presented, in the form of cubes and slices, to be evaluated by the panelists at room temperature in a properly ventilated and well-lit sensory evaluation laboratory with individual cabins. Each panelist evaluated each sample 3 times and descriptive scores were awarded for different characteristics of each parameter within a total of 100 . This evaluation scale was prepared by the assessors, after training sessions and discussions, and ranged from 1 to 100 for each parameter (odor, flavor and texture).

\section{Statistical Analysis}

Results obtained were statistically analyzed using ANOVA and the descriptive sensory scores were further subjected to PCA and HCA as described by Steel et al. (1997) to evaluate the influence of milk sources (cow and buffalo), starter cultures, and ripening temperatures on sensory quality of Cheddar cheese.

\section{RESULTS AND DISCUSSION}

\section{Composition of Milk Samples}

Milk samples from cow and buffalo standardized at $4.0 \%$ fat levels were analyzed for composition. The 
composition of cow milk was $3.09 \%, 3.86 \%, 0.13 \%$, 6.65 , and $11.20 \%$ protein, lactose, acidity, $\mathrm{pH}$, and total solids, respectively, whereas that of buffalo milk was $3.65 \%, 4.68 \%, 0.14 \%, 6.62$, and $12.60 \%$, respectively. This showed the substantial differences between various components of both milk types, particularly with regard to protein and lactose.

\section{Descriptive Sensory Evaluation of Cheddar Cheese}

The mean score values obtained for various odor traits are given in Table 1. The results illustrated that, with the progression of ripening, the odor of the cheese increased, with higher scores after $120 \mathrm{~d}$ of ripening compared with those at $60 \mathrm{~d}$. However, the "sweet" trait decreased with time, with means scores of 21.26 and 19.22 after 60 and $120 \mathrm{~d}$ of storage, respectively. The mean scores obtained for the buffalo milk Cheddar cheese (11.71) were higher than those for cow milk cheese (11.55); however, the cheese samples prepared using commercial cultures mostly received higher scores for odor compared with that of indigenous cultures in both cow and buffalo milk. The development of odor during ripening was considerably influenced by the elevated temperature, as the average scores attained by the cheese samples ripened at $12^{\circ} \mathrm{C}$ were higher compared with those ripened at $4^{\circ} \mathrm{C}$, with no consideration of starter cultures and milk types.

The sensory scores awarded to various flavor attributes of Cheddar cheese (Table 2) illustrated that mean scoring of buffalo milk cheese was significantly higher (12.27) than that of cow milk cheese (11.73). Cheddar cheese samples prepared from commercial cultures received slightly higher mean score values compared with those of indigenous cultures. The cheese samples ripened at $12^{\circ} \mathrm{C}$ received higher mean scores for flavor attributes than those ripened at $4^{\circ} \mathrm{C}$, without consideration of milk type or starter cultures used. As ripening progressed, all flavor characteristics increased in intensity and received significantly higher scores after $120 \mathrm{~d}$ of storage compared with $60 \mathrm{~d}$, except the "salty" trait, which reduced with time.

The mean scores for different characteristics of cheese texture (Table 3) were significantly higher for the samples prepared from buffalo milk (25.62) compared with those prepared from cow milk (21.89). However, cheese "maturity" was similar in both groups of Cheddar cheeses. The use of indigenous starter cultures considerably influenced the texture of cheese, as the samples manufactured from indigenous cultures had significantly higher scores compared with commercial cultures. Individually, the "firmness" and "grainy" qualities of texture were enhanced by the indigenous cultures. The elevated ripening temperature also enhanced the texture development; mean scoring for all the cheese samples ripened at $12^{\circ} \mathrm{C}$ was higher compared with those ripened at $4^{\circ} \mathrm{C}$. The "firmness" and "maturity" of cheese texture increased, whereas "pasty" behavior decreased by ripening at higher temperature. During ripening, cheese texture improved and, after 120 d of ripening, all the attributes except "pasty" were awarded significantly higher scores compared with those at $60 \mathrm{~d}$. The "pasty" characteristic decreased with time, however.

Buffalo milk cheese received appreciably higher scores for odor, flavor, and texture than cow milk

Table 1. Effect of milk types (cow or buffalo), starter cultures (commercial or indigenous), and ripening temperatures on descriptive sensory scores of cheese odor

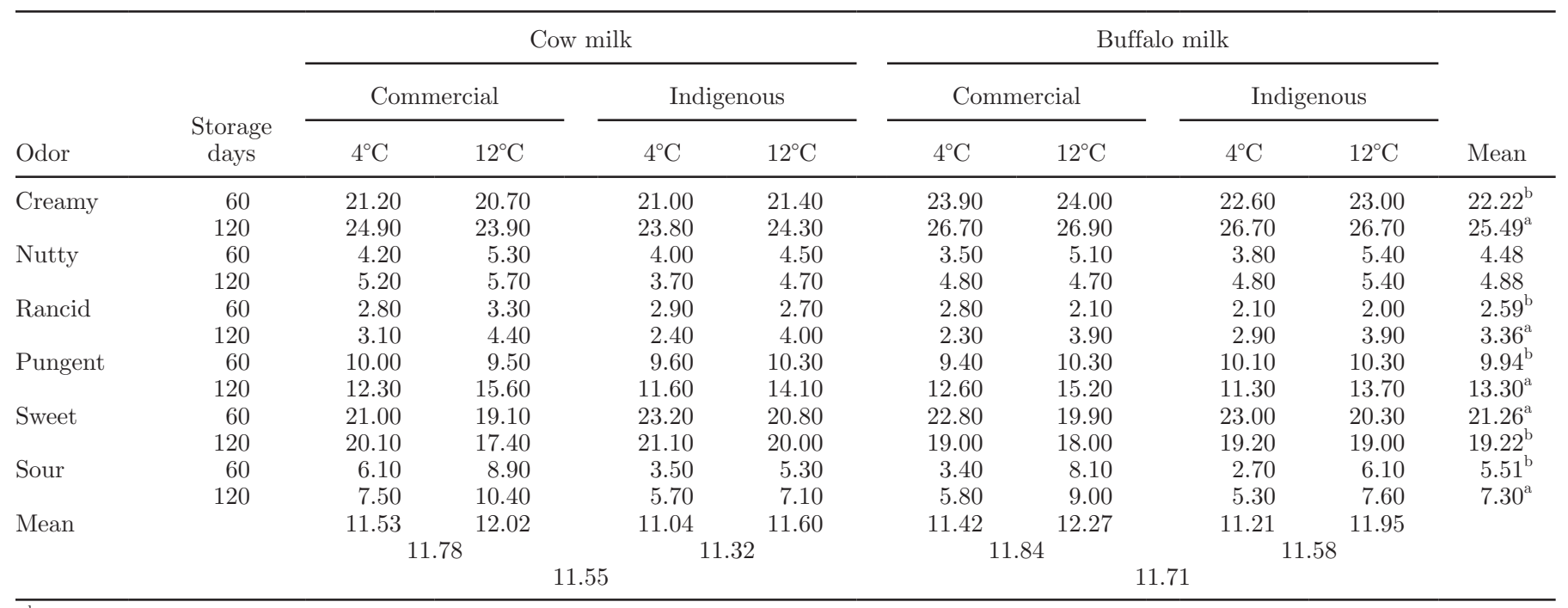

\footnotetext{
${ }^{\mathrm{a}, \mathrm{b}}$ Values with the same letters in a row or column indicate that samples do not differ significantly at a significance level of $5 \%$.
} 
Table 2. Effect of milk types (cow or buffalo), starter cultures (commercial or indigenous), ripening temperatures, and period on descriptive sensory scores of cheese flavor

\begin{tabular}{|c|c|c|c|c|c|c|c|c|c|c|}
\hline \multirow{2}{*}{ Flavor } & \multirow{2}{*}{$\begin{array}{c}\text { Storage } \\
\text { days }\end{array}$} & \multicolumn{4}{|c|}{ Cow milk } & \multicolumn{4}{|c|}{ Buffalo milk } & \multirow{2}{*}{ Mean } \\
\hline & & \multicolumn{2}{|c|}{ Commercial } & \multicolumn{2}{|c|}{ Indigenous } & \multicolumn{2}{|c|}{ Commercial } & \multicolumn{2}{|c|}{ Indigenous } & \\
\hline \multirow[t]{2}{*}{ Creamy } & 60 & 21.20 & 25.50 & 24.90 & 26.70 & 29.10 & 30.30 & 29.40 & 31.00 & $27.26^{\mathrm{b}}$ \\
\hline & 120 & 25.00 & 26.60 & 26.80 & 27.50 & 30.50 & 32.00 & 31.30 & 30.50 & $28.78^{\mathrm{a}}$ \\
\hline Acidic & 60 & 17.20 & 18.60 & 15.20 & 17.10 & 16.50 & 18.80 & 15.60 & 17.30 & $17.04^{\mathrm{b}}$ \\
\hline Rancid & 120 & 6.80 & 9.20 & 7.50 & 9.80 & 7.60 & 8.50 & 7.60 & 9.30 & $8.29^{\mathrm{a}}$ \\
\hline \multirow[t]{2}{*}{ Bitter } & 60 & 9.20 & 8.90 & 6.20 & 6.20 & 9.30 & 9.50 & 5.60 & 5.60 & $7.56^{\mathrm{b}}$ \\
\hline & 120 & 11.10 & 11.50 & 6.60 & 7.00 & 11.00 & 11.50 & 7.20 & 6.50 & $9.05^{\mathrm{a}}$ \\
\hline \multirow{2}{*}{ Salty } & 60 & 22.20 & 22.00 & 21.60 & 21.60 & 22.10 & 22.10 & 21.90 & 21.70 & $21.90^{\mathrm{a}}$ \\
\hline & 120 & 20.20 & 20.20 & 20.50 & 20.90 & 20.80 & 20.90 & 21.50 & 22.00 & $20.88^{\mathrm{b}}$ \\
\hline \multirow[t]{2}{*}{ Sweet } & 60 & 11.20 & 11.30 & 14.80 & 13.90 & 11.40 & 10.60 & 13.00 & 12.30 & $12.31^{\mathrm{b}}$ \\
\hline & 120 & 15.70 & 14.00 & 20.10 & 20.20 & 13.90 & 14.00 & 20.70 & 20.30 & $17.36^{\mathrm{a}}$ \\
\hline Soapy & 120 & 8.50 & 8.10 & 8.10 & 8.40 & 5.00 & 5.00 & 5.30 & 5.50 & $6.74^{\mathrm{a}}$ \\
\hline \multirow[t]{2}{*}{ Sour } & 60 & 9.90 & 10.00 & 5.00 & 5.00 & 9.80 & 9.80 & 5.00 & 5.00 & $7.44^{\mathrm{b}}$ \\
\hline & 120 & 12.90 & 12.80 & 7.90 & 7.80 & 12.70 & 13.00 & 8.00 & 8.10 & $10.40^{\mathrm{a}}$ \\
\hline \multirow[t]{2}{*}{ Mean } & & 11.71 & 12.18 & 11.32 & 11.72 & 12.30 & 12.73 & 11.92 & 12.12 & \\
\hline & & \multicolumn{2}{|c|}{11.95} & \multicolumn{2}{|c|}{11.52} & & & \multicolumn{2}{|c|}{12.02} & \\
\hline
\end{tabular}

$\overline{\mathrm{a}, \mathrm{b}}$ Values with the same letters in a row or column indicate that samples do not differ significantly at a significance level of $5 \%$.

cheese, perhaps owing to the substantial differences in milk composition. Buffalo milk is richer in fat, lactose, protein, and minerals than cow milk, and the capacity of milk to be acidified is higher for buffalo than cow milk (Fundora et al., 2001; Ahmad et al., 2008). Odor, flavor, and texture development in cheese during ripening is the result of complex microbiological and biochemical processes and involves the enzymatic digestion of the curd components (Choisy et al., 2000; Singh et al., 2003; Farkye, 2004). Cheese flavor is a complex combination of several hundred components, developed through biochemical changes, that occur during the ripening (Forde and Fitzgerald, 2000; Kwak et al., 2003; Lucey et al., 2003).

Table 3. Effect of milk types (cow or buffalo), starter cultures (commercial or indigenous), ripening temperatures, and period on descriptive sensory scores of cheese texture

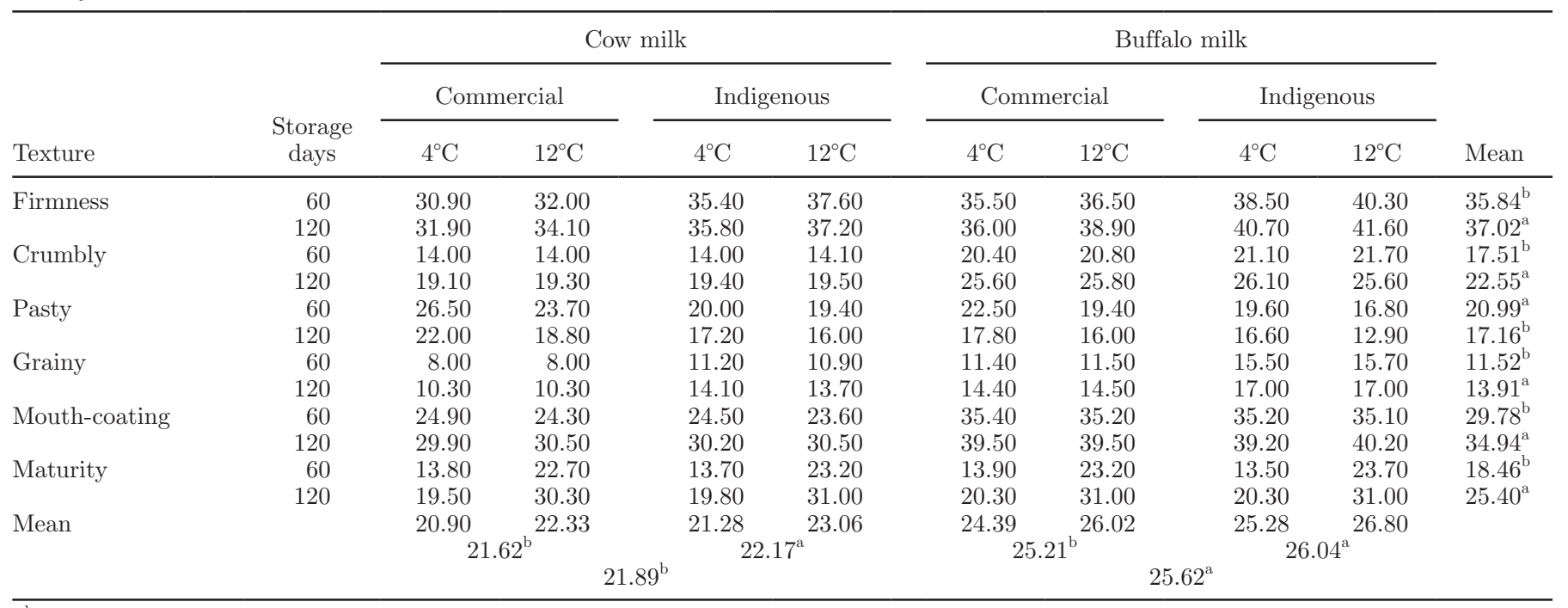

\footnotetext{
${ }^{\mathrm{a}, \mathrm{b}}$ Values with the same letters within a row or column indicate that samples do not differ significantly at a significance level of $5 \%$.
} 
Elevated ripening temperature significantly accelerated an increase in the sensory characteristics due to the integration of various metabolic processes (McSweeney, 2004; Ong et al., 2007). The higher temperature accelerates the metabolic activities (Azarnia et al., 2006) and enhances the volatility of flavor compounds (Drake et al., 2005).

The starter cultures play a key role in flavor and texture development during ripening of Cheddar cheese through biochemical and microbiological reactions (Azarnia et al., 2006). The indigenous cultures were found to be superior to commercial cultures regarding growth and activity, which enhanced the sensory characteristics. The lower scoring for "acidic," "sour," and "bitter" flavors in cheese prepared from indigenous cultures, rather than commercial cultures, validates the superiority of indigenous cultures.

\section{Multivariate Statistical Analysis of Sensory Scores}

Principal component (PC)1 accounted for most of the variation $(45 \%)$ between the sensory characteristics of the Cheddar cheese samples separated on the basis of ripening period, whereas $\mathrm{PC} 2$ accounted for $27 \%$ of the variation between the cheese samples and distinguished the cheese by milk source and starter culture (Figure 1). The results for $\mathrm{PC} 1$ and $\mathrm{PC} 2$ significantly $(P<$ 0.05 ) discriminated between the cheeses and accounted for a cumulative variation of $72 \%$.

Regarding the sensory scores, cheese samples at 60 $\mathrm{d}$ of ripening were grouped on one side of the plot, whereas the same sample after $120 \mathrm{~d}$ fell on the other side. This demonstrated that ripening period influenced the sensory perception of all samples regardless of milk source, starter cultures, and ripening temperatures. The cheese samples prepared from cow and buffalo milk were located separately on the bi-plot. Similarly, the cheese samples manufactured from commercial and indigenous cultures showed a considerable difference in the sensory scores by their placements on opposite sides of the plot. Mostly, the samples prepared from cow milk and commercial starter cultures were grouped together, and those of buffalo milk and indigenous cultures were jointly placed on the other side. The relative positions of the cheese samples on the bi-plot is a useful index of the effect of the milk sources, starter cultures, ripening

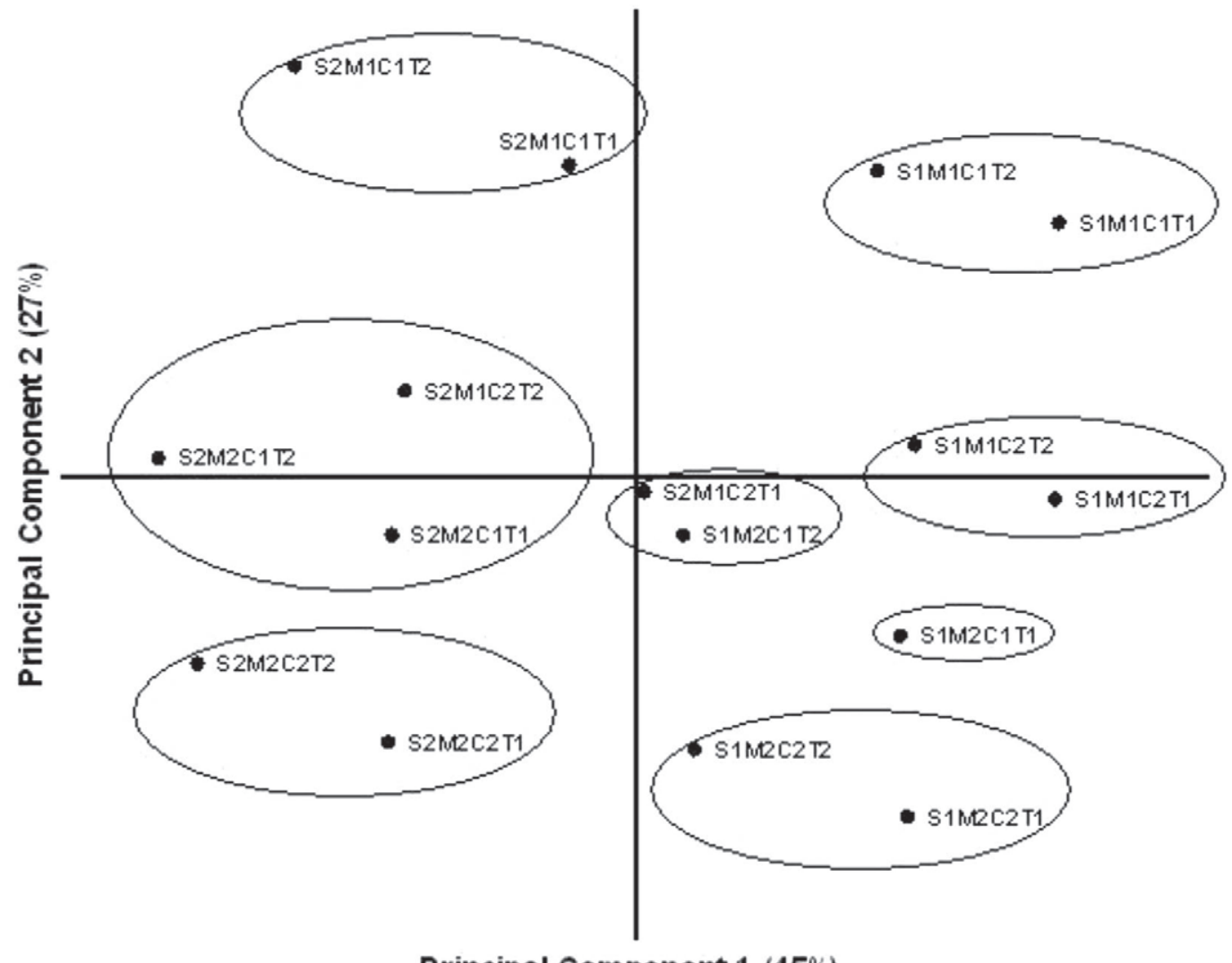

Principal Component 1 (45\%)

Figure 1. Principal component $(\mathrm{PC})$ analysis of the first $2 \mathrm{PC}$ of descriptive sensory analysis of Cheddar cheese. S1 = ripening of 60 d; $\mathrm{S} 2$ $=$ ripening of $120 \mathrm{~d} ; \mathrm{M} 1=$ cow milk cheese; $\mathrm{M} 2=$ buffalo milk cheese; $\mathrm{C} 1=$ commercial cultures; $\mathrm{C} 2=$ indigenous cultures; $\mathrm{T} 1=$ ripening at $4^{\circ} \mathrm{C}$; $\mathrm{T} 2=$ ripening at $12^{\circ} \mathrm{C}$. 


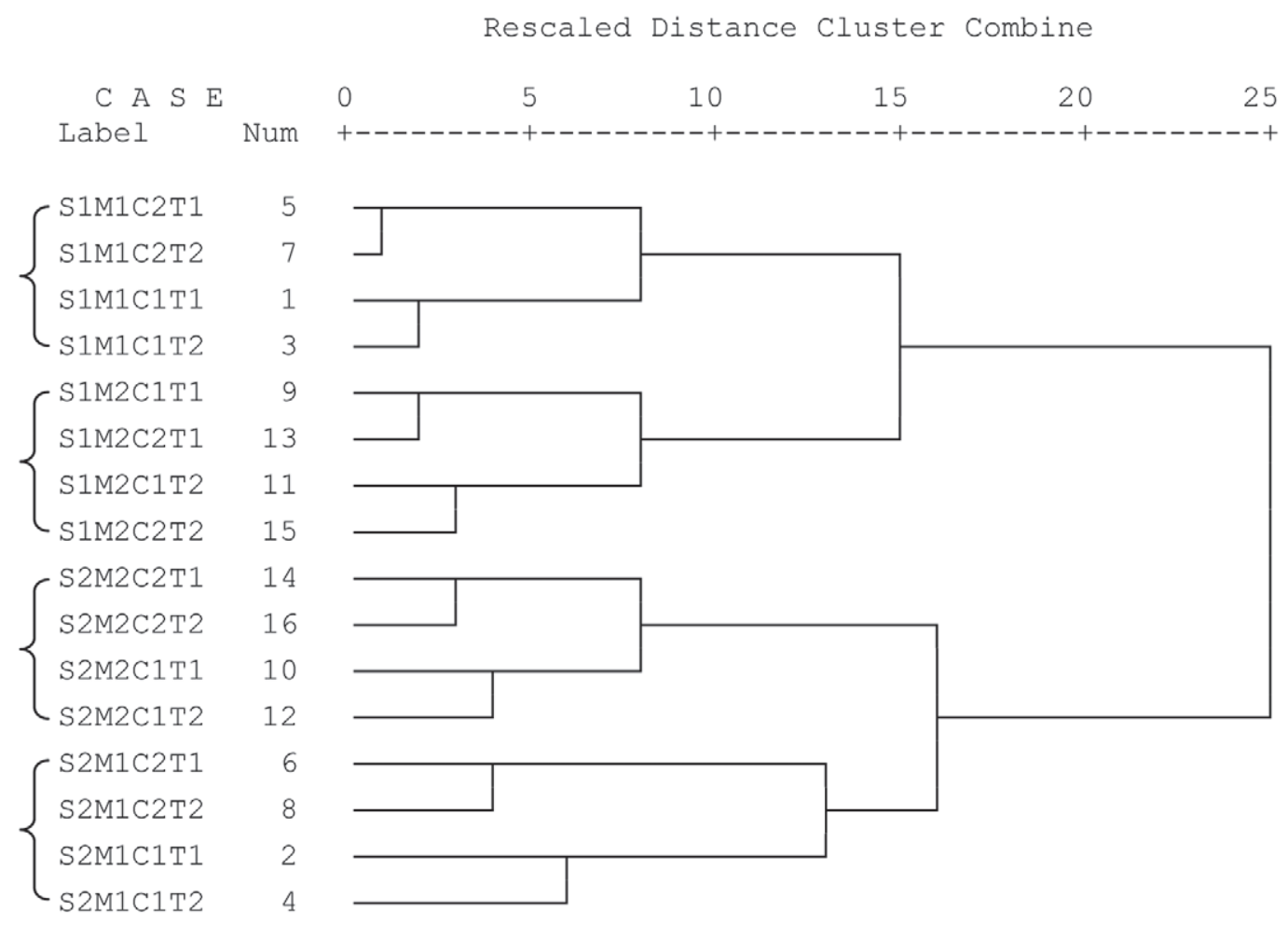

Figure 2. Dendrogram obtained from hierarchical cluster analysis $(\mathrm{HCA})$ of sensory data of Cheddar cheese. S1 = ripening of $60 \mathrm{~d}$; S2 = ripening of $120 \mathrm{~d} ; \mathrm{M} 1=\mathrm{cow}$ milk cheese; $\mathrm{M} 2=$ buffalo milk cheese; $\mathrm{C} 1=$ commercial cultures; $\mathrm{C} 2=$ indigenous cultures; $\mathrm{T} 1=$ ripening at $4^{\circ} \mathrm{C} ; \mathrm{T} 2=$ ripening at $12^{\circ} \mathrm{C}$.

temperatures, and periods and how the sensory profile of cheese samples differ from each other.

Hierarchical cluster analysis offers a basis for interpretation of the bi-plot and the identification of clusters of closely related samples. An $\mathrm{HCA}$ on the raw data was used to cluster closely related samples (Figure 2 ) in terms of sensory characteristics and generated 4 main clusters. The first cluster identified by HCA grouped the cheese samples prepared from cow milk and ripened for $60 \mathrm{~d}$. It had subgroups differentiated by the starter cultures used and ripening temperatures. Cluster 2 contained cheeses for buffalo milk ripened for $60 \mathrm{~d}$ and also had subgroupings. One subgroup was based on low ripening temperature and the second on higher temperature $\left(12^{\circ} \mathrm{C}\right)$, suggesting the considerable effect of ripening temperatures on the development of sensory characteristics. Similar variation in sensory profile is illustrated across $\mathrm{PC} 1$ with acceleration in ripening temperature. Cluster 3 grouped the buffalo milk cheese ripened for $120 \mathrm{~d}$ and was subdivided into 2 subgroups based on the starter cultures used and ripening temperatures. The fourth cluster had the cheese samples manufactured from cow milk ripened for $60 \mathrm{~d}$ and was subdivided in the same manner as the first 3 .
The first 2 and last 2 clusters were grouped in 2 main consortiums based on ripening periods.

Grouping and subgrouping on the dendrogram and the positions of cheese samples on PCA plot indicated that all parameters significantly influenced the sensory characteristics.

\section{CONCLUSIONS}

We concluded that cheese prepared from buffalo milk using indigenous cultures scored significantly higher for most of the sensory attributes compared with that from cow milk and using commercial cultures, and elevated temperature perceptibly accelerated the development of sensory characteristics during ripening.

\section{REFERENCES}

Ahmad, S., I. Gaucher, F. Rousseau, E. Beaucher, M. Piot, J. F. Grongnet, and F. Gaucheron. 2008. Effects of acidification on physico-chemical characteristics of buffalo milk: a comparison with cow's milk. Food Chem. 106:11-17.

AOAC. 1990. Official Methods of Analysis. 15th ed. Vol. 2. Association of Official Analytical Chemists, Arlington, VA.

Azarnia, S., N. Robert, and B. Lee. 2006. Biotechnological methods to accelerate Cheddar cheese ripening. Crit. Rev. Biotechnol. $26: 121-143$ 
Bodyfelt, F. W., J. Tobias, and G. M. Trout. 1988. Sensory evaluation of cheese. Pages 300-376 in The Sensory Evaluation of Dairy Products. F. W. Bodyfelt, ed. Van Nostrand Reinhold, New York, NY.

Caspia, E. L., P. C. Coggins, M. W. Schilling, Y. Yoon, and C. H. White. 2006. The relationship between consumer acceptability and descriptive sensory attributes in Cheddar cheese. J. Sens. Stud. $21: 112-127$.

Choisy, C., M. Desmazeaud, J. C. Gripon, G. Lamberet, and J. Lenoir. 2000. The biochemistry of ripening. Pages $82-151$ in Cheese Making: From Science to Quality Assurance. 2nd ed. A. Eck and J. C. Gillis, ed. Lavoisier, Paris, France

Downey, G., E. Sheehan, C. Delahunty, D. O'Callaghan, T. Guinee, and V. Howard. 2005. Prediction of maturity and sensory attributes of Cheddar cheese using near-infrared spectroscopy. Int. Dairy J. 15:701-709.

Drake, M. A., M. D. Yates, and P. D. Gerard. 2005. Impact of serving temperature on trained panel perception of cheddar cheese flavor attributes. J. Sens. Stud. 20:147-155.

Farkye, N. Y. 2004. Cheese technology. Int. J. Dairy Technol. 57:9198.

Forde, A., and G. F. Fitzgerald. 2000. Biotechnological approaches to the understanding and improvement of mature cheese flavor. Curr. Opin. Biotechnol. 11:484-489.

Fox, P. F. 1989. Accelerated cheese ripening. Food Biotechnol. 2:133141.

Fox, P. F., T. P. Guinee, T. M. Cogan, and P. L. H. McSweeney. 2000 Fundamentals of Cheese Science. Aspen Publishers Inc., Gaithersburg, MD.

Fundora, O., M. E. Gonzalez, O. Lezcano, A. Montejo, N. Pompa, and A. V. Enriquez. 2001. A comparative study of milk composition and stability of Murrah river buffaloes and Holstein cows grazing star grass. Cuban J. Agric. Sci. 35:219-222.

Hannon, J. A., M. G. Wilkinson, C. M. Delahunty, J. M. Wallace, P. A. Morrissey, and T. P. Beresford. 2005. Application of descriptive sensory analysis and key chemical indices to assess the impact of elevated ripening temperatures on the acceleration of Cheddar cheese ripening. Int. Dairy J. 15:263-273.

Heisserer, D. M., and E. Chambers. 1993. Determination of the sensory flavor attributes of aged natural cheese. J. Sens. Stud. 8:121-132.

House, K. A., and T. E. Acree. 2002. Sensory impact of free fatty acids on the aroma of a model Cheddar cheese. Food Qual. Prefer. 13:481-488.

Kwak, H. S., Y. S. Ju, H. J. Ahn, J. Ahn, and S. Lee. 2003. Microencapsulated iron fortification and flavor development in Cheddar cheese. Asian-australas. J. Anim. Sci. 16:1205-1211.

Law, B. A. 2001. Controlled and accelerated cheese ripening: The research base for new technologies. Int. Dairy J. 11:383-398.

Lee, B. H., L. C. Laleye, R. E. Simard, M. H. Munsch, and R. A. Holley. 1990. Influence of homo-fermentative lactobacilli on the microflora and soluble nitrogen components in cheddar cheese. J. Food Sci. 55:391-397.

Lucey, J. A., M. E. Johnson, and D. S. Horne. 2003. Invited review: Perspectives on the basis of the rheology and texture properties of cheese. J. Dairy Sci. 86:2725-2743.

McSweeney, P. L. H. 2004. Biochemistry of cheese ripening. Int. J. Dairy Technol. 57:127-144.

McSweeney, P. L. H., and M. J. Sousa. 2000. Biochemical pathways for the production of flavour compounds in cheese during ripening: A review. Lait 80:293-324.

Muir, D. D., and E. A. Hunter. 1992. Sensory evaluation of Cheddar cheese: The relation of sensory properties to perception of maturity. J. Soc. Dairy Technol. 45:23-30.

Murtaza, M. A., S. U. Rehman, F. M. Anjum, N. Huma, O. M. Tarar, and G. Mueen-ud-Din. 2012. Organic acids contents of buffalo milk Cheddar cheese as influenced by accelerated ripening and sodium salt. J. Food Biochem. 36:99-106.

Murtaza, M. A., S. U. Rehman, F. M. Anjum, and H. Nawaz. 2008 Nutritional comparison of cow and buffalo milk Cheddar cheese. Pak. J. Nutr. 7:509-512

Ong, L., A. Henriksson, and N. P. Shah. 2007. Proteolytic pattern and organic acid profiles of probiotic Cheddar cheese as influenced by probiotic strains of Lactobacillus acidophilus, Lb. paracasei, Lb. casei or Bifidobacterium sp. Int. Dairy J. 17:67-78.

Pollard, A., F. Sherkat, M. G. Seuret, and A. L. Halmos. 2003. Textural changes of natural Cheddar cheese during the maturation process. J. Food Sci. 68:2011-2016.

Rehman, S. U., J. M. Banks, E. Y. Brechany, D. D. Muir, P. L. H. McSweeney, and P. F. Fox. 2000. Influence of ripening temperature on the volatiles profile and flavour of Cheddar cheese made from raw or pasteurized milk. Int. Dairy J. 10:55-65.

Scott, R. 1981. Selected cheese recipes. Pages 367-369 in Cheese Making Practice. Applied Science Publishers Ltd., London, UK.

Singh, T. K., M. A. Drake, and K. R. Cadwallader. 2003. Flavor of cheddar cheese: A chemical and sensory perspective. Comp. Rev. Food Sci. Food Saf. 2:139-162.

Smit, G., B. A. Smit, J. M. Wim, and J. M. Engels. 2005. Flavour formation by lactic acid bacteria and biochemical flavour profiling of cheese products. FEMS Microbiol. Rev. 29:591-610.

Steel, R. G. D., J. H. Torrie, and D. A. Dickey. 1997. Principles and Procedures of Statistics. A Biometrical Approach. 3rd ed. McGraw Hill Book Co. Inc., New York, NY.

Stone, H., and J. L. Sidel. 1985. Sensory Evaluation Practices. Academic Press, Orlando, FL.

Varnam, A. H., and J. P. Sutherland. 1994. Milk and Milk Products. Chapman \& Hall, New York, NY.

Wilkinson, M. G. 1993. Acceleration of cheese ripening. Pages 523-555 in Cheese: Chemistry, Physics and Microbiology. Vol. 1. Chapman \& Hall. London. UK. 